treatment adherence (Turkington et al, 2006). Trials of brief therapy demonstrate protection against depression and relapse. Those who do relapse have a delayed time to admission and significantly reduced time spent in hospital. Turkington et al also highlight the role of mental health nurses trained in brief CBT for schizophrenia as a supplement to case management and family interventions. More detailed therapy can be focused on individuals who are treatment resistant.

The use of CBT in the treatment of psychosis remains underdeveloped compared with its use for neurotic disorders. Further complications are its restricted availability in the NHS, the paucity of trained therapists and haphazard CBT supervision for psychiatric trainees. We believe that CBT should be further emphasised during psychotherapy supervision and routine consultant supervision for psychiatric trainees.

There is also a case for longer-term individual, group and family dynamic psychotherapies within early intervention teams (Martindale, 2007). Less evident are the benefits of non-specific, supportive counselling (Grich, 2002).

Drury, V., Birchwood, M. \& Cochrane, R. (2000) Cognitive therapy and recovery from acute psychosis: a controlled trial. 3: Fiveyear follow-up. British Journal of Psychiatry, 177, 8-14.

Freeman, F. \& Garety, P. (2006) Helping patients with paranoid and suspicious thoughts: cognitive-behavioural approach. Advances in Psychiatric Treatment, 12, 404-415.

Grich, E. (2002) A review of the current evidence for the use of psychological interventions in psychosis. International Journal of Psychosocial Rehabilitation, 6, 79-88.

Martindale, B. (2007) Psychodynamic contributions to early intervention in psychosis. Advances in Psychiatric Treatment, 13, 34-42.

Turkington, D., Kingdon, D., Rathod, S., et al (2006) Outcomes of an effectiveness trial of cognitive-behavioural intervention by mental health nurses in schizophrenia. British Journal of Psychiatry, 189, 36-40.

Gunjan Khandpur Senior House Officer (Adult Psychiatry), St Michael's Hospital, Warwick, UK (Email: gunjan_khandpur15@ yahoo.co.in)

Suraj Pal Singh Staff Grade, St Michael's Hospital, Warwick doi: 10.1192/apt.190.2.155b

\section{Relevance of attachment theory}

Kenneth Ma (2007) very aptly emphasises the significance of attachment theory in relation to the therapeutic relationship, which has important implications regarding the treatment and prognosis of psychiatric disorders. Although an offspring of psychoanalysis, attachment theory has been conspicuously neglected for a long time by the main proponents of Freud and Klein. Fonagy (2001) has attempted to integrate the overlapping areas of attachment theory and psychoanalysis, and deserves credit for reawakening interest in Bowlby's work. Although some of the criticisms of attachment theory are not unfounded, there is evidence that concepts of the theory can be used in making significant predictions regarding relationships, styles of coping with stressful situations, and communication between couples (Brennan \& Shaver, 1994). Similarly, Holmes ( 2000) has suggested that attachment theory can help with clinical listening and identifying, and intervening with different narrative styles in therapy.

However, it is essential that we guard ourselves against becoming overoptimistic about attachment theory. We need to remind ourselves that, although important, Bowlby's observations were based on children who had been separated from their primary caregivers during the Second World War (Lemma, 2003). In other words, attachment theory was based on behaviours that occurred during stressful situations rather than under normal circumstances. As Field (1996) has pointed out, a wider and in-depth understanding of attachment requires observation of interactions between mother and infant during natural and non-stressful situations.

I concur with Dr Ma that more rigorous research is required in the areas highlighted in his two articles (Ma, 2006, 2007). The idea of using attachment theory for service configuration seems to me very overambitious.

Brennan, K. \& Shaver, P. (1994) Dimensions of adult attachment, affect regulation and romantic relationship functioning. Personality and Social Psychology Bulletin, 21, 267-283.

Field, T. (1996) Attachment and separation in young children. Annual Review of Psychology, 47, 541-562.

Fonagy, P. (2001) Attachment Theory and Psychoanalysis. Other Press.

Holmes, J. (2000) Attachment theory and psychoanalysis: a rapprochement. British Journal of Psychotherapy, 17, 157-172.

Lemma, A. (2003) Introduction to the Practice of Psychoanalytic Psychotherapy. John Wiley \& Sons.

Ma, K. (2006) Attachment theory in adult psychiatry. Part 1: Conceptualisations, measurement and clinical research findings. Advances in Psychiatric Treatment, 12, 440-449.

Ma, K. (2007) Attachment theory in adult psychiatry. Part 2: Importance to the therapeutic relationship. Advances in Psychiatric Treatment, 13, 10-16.

Tanvir A. Rana Visiting Senior Lecturer, Faculty of Health and Sciences, Staffordshire University, Stafford ST1 80D, UK. Email: tanvir_rana@hotmail.com.

doi: 10.1192/apt.190.2.156 